\title{
Using Roger's Diffusion of Innovation Theory to Implement the Healthy Schools National Accreditation
}

\author{
Basema Mohammad Nofal, ${ }^{1}$, Inaam Khalaf ${ }^{2}$ \\ ${ }^{1}$ Part-Time Lecturer, School of Nursing, the University of Jordan. Amman. Jordan, ${ }^{2}$ Professor, School of \\ Nursing, the University of Jordan
}

\begin{abstract}
Background: In Jordan, The Healthy School National Accreditation has been introduced in 2008 as a national health-promoting school program where schools are invited to voluntarily join the accreditation. Unfortunately, financial challenges and lack of resources among many other factors led to very low enrollment rate. Method: Adopting a selected change theory can be beneficial in making the decision and successfully implementing the intended change. Rogers's diffusion of innovations theory was adopted by a public school administration to join the accreditation. This theory provides an explanation on how and at what rate new innovations take place and spread out over time in any system. The school health committee went through the five stages proposed by the theory and successfully implemented the accreditation.
\end{abstract}

Conclusion: Adopting Rogers's diffusion of innovations theory can be beneficial iN implementing the school health-promoting programs.

Implication for School Health: School administrators, school health nurses and school health teachers are strongly advised to adopt this theory while they are considering joining the school health-promoting programs.

Keywords: Health-promoting school; Healthy School National Accreditation; Rogers's diffusion of innovations theory.

\section{Introduction}

Health promotion of youth is globally considered a high priority. Since students spend a long time in schools, schools have the chance to play a vital role in promoting students' health and well-being. Nowadays, HealthPromoting School (HPS) is a well-established and sound public health approach to addressing health outcomes within an educational environment. The concept of HPS was first introduced by the World Health Organization (WHO) in 1980s as an effective multifaceted approach to ensure promoting students health and academic achievement ${ }^{[1]}$. HPS is defined as "school that fosters

\section{Correspondence author:}

Basema Mohammad Nofal RN, MSN, $\mathrm{PhD}(\mathrm{c})$, School of Nursing, the University of Jordan. Amman. Jordan. Email: basemanofal@yahoo.com Tel: 00962798842900. health and learning with all the measures at its disposal, and strives to provide supportive environments for health and a range of key school health education and promotion programs and services." [2]. Later, the WHO developed a holistic HPS framework to help schools in developing, implementing, and evaluating the HPS programs. This framework stresses three main points: health education, changing social and physical environment, and involving students' families and/or communities ${ }^{[3]}$.

The WHO strongly suggested schools to adopt, implement, and investigate the effectiveness of this framework against a wide range of health outcomes such as physical activity and nutrition. Thus, the concept has been widely adopted worldwide but mostly by high incomecountries. In a systematic review byFurley and Goldfeld ${ }^{[4]}$ on the randomized clinical trials that adopt the WHO framework, 59 out of 67 studies were found to be conducted in high income countries. This highlighted 
the gap in adopting and implementing the HPS programs between high and low-middle income countries as these programs are costly and require a lot of resources.

In Jordan, a low-middle income country, the concept of the HPS was translated into the Healthy School National Accreditation (HSNA) by the Royal Health Awareness Society, in partnership with the Ministry of Health $(\mathrm{MOH})$ and the Ministry of Education (MOE). It was launched in 2008, where schools have been voluntarily encouraged to apply for any level of the accreditation including the bronze, the silver, and the golden levels ${ }^{[5]}$. The program is carried through national health standards that participating schools usually trained and supervised to implement them successfully. Standards cover ten chapters including management and leadership, healthy school environment, safe school environment, clean school environment, health education, nutrition, physical activity, health services, social and psychological support, and staff and community participation ${ }^{[5]}$.

\section{Problem statement}

Children and youth are considered the greatest natural source for their nations, and the future of any nation strongly depends on how well they care for their children and youth. Thus, students must receive a comprehensive physical, social, mental and psychological health care at schools. Moreover, preventing and controlling the major risk factors of non-communicable diseases such as tobacco use, physical inactivity, and unhealthy diet is the focus of the WHO's work with children and adolescents ${ }^{[6]}$. Creating healthy, clean, and safe school environment in addition to teaching students the healthy lifestyle practices through HPS programs can tackle these risk factors at early age and ensure healthier generations.

Voluntarily implementing a comprehensive program in a developing country can be challenging. Making the decision whether to join the accreditation depends mainly on school principals' and school health teachers' (SHTs) willingness. Unfortunately, after 10 years of launching the HSNA, the enrollment rate of schools to the end of the academic year 2018-2019 was still around $3 \%$ (174 schools) ${ }^{[5]}$. This indicates the need to raise awareness and introduce new ways of thinking. Following a selected change theory may help the school administrations make an informed decisions and facilitate the implementation process.
Rogers's diffusion of innovation theory

Rogers's diffusion of innovation theory (RDIT) is selected by the SHC at this school to help make a decision and guide the implementation process. The theory explains the process of change and how a new innovation takes hold and spreads throughout a system. It focuses on the perceived innovation attributes that will increasingly drive adoption. The five attributes of an innovation are relative advantage, compatibility, complexity, trialability, and observability. Also, the theory provides five steps necessary to promote the adoption of a new idea:knowledge, persuasion, decision, implementation, and confirmation ${ }^{[7]}$.

Knowledge is produced when an individual or organization is exposed to an existing innovation and acquires some understanding about its mechanisms and functions. To reach the persuasion stage, the individual or organization must form a view toward the innovation based on its perceived attributes. For decisionto occur, the individual or organization must be involved in an activity that would ultimately require him or her to make a choice between using and dismissing the innovation. For Adoption to occur, the individual or organization must decide that the innovation is the best available option to meet the intended goals. In the implementation stage, the individual or organization actually implements the innovation. Finally, the confirmation stage occurs when people are presented with the innovation on the long term ${ }^{[7]}$.

\section{Applying RDIT to implement the HSNA}

\section{Description of the school}

This school is a large secondary public school that receives students from seventh to twelfth grades. It was established in 1982 in Amman, and annually receives about 900 students. Fifty-one academic and administrative employees and two housekeepers are working in this school. All teachers are at least Bachelor degree holders in different educational specialties. The school lack a school health clinic and health workers. Instead, the school principal assigns one teacher to follow students' health issues and he/ she is called the SHT. 


\section{Assessment}

One pre-requisite in RDIT is to assess the previous conditions, practices and problems ${ }^{[7]}$. Accordingly, a comprehensive assessment was conducted based on the ten accreditation chapters. Regarding the clean, safe, and healthy environment, the school environment was suffering from many chronic problems. Among them were the lack of the main gate which allows strangers to enter school and may expose students for robbery; short school wall which facilitates students escape from school as well as permitting strangers to enter school. Moreover, the wall is usually moist with reek and molds. Classes are small and crowded, with some broken desks, no curtains to protect students from sunlight, in addition to some lightening problems. Also, there were no shaded yards to allow students to play safely during their break time. Insufficient drinking water, limited number of bathrooms with low level of sanitation were also among the main problems. Also, the sidewalk is destroyed and people used to park there. Finally, lack of a pedestrian path makes it difficult for students to cross the road.

Assessing health education revealed scarcity in the educational activities and they found to be fragmented and limited to individualized initiatives from the SHT. Moreover, health education is conducted in a form of lectures. The school canteen was unorganized, dirty, with no fridge and no sink. Moreover, canteen was depending on sales of unhealthy snacks. Assessing the physical activity revealed absence of sport room and equipment, with only one sport teacher who was assigned for the entire school. Also, school's yards were broken and unequipped for the different sports. Finally, sport's classes often used to be devoted for teaching other subjects.

Assessing school health services revealed no health room, nor school health nurse. Beside her regular academic load, the SHT follows all students' health issues. Also, a nurse and a dentist from the local health care center make annual visits to conduct vision and dental screening and send reports to parents to follow up. Class teachers usually measure height and weight and compare results with the growth and developmental charts and send reports to parents to follow up. Regarding the social and psychological services, the school counsellor usually gives routine group counseling sessions to students and parents that covers topics such as learning disabilities, effective studying habits, and bullying. Assessing families and community participation revealed limited collaboration with parents and local community agencies.

\section{Knowledge stage:}

The school administration had been introduced to the HSNA program through the official letters received from the MOE at the beginning of the academic year to invite schools to voluntarily join the accreditation. Consequently, the school principal and the SHT gained information about definition, goals, philosophy, benefits, process of implementation and kinds of evaluation.

\section{Persuasion stage:}

After gathering all needed information, the school principal and the SHC members met to discuss and evaluate the five attributes of the accreditation. Regarding the relative advantages, they realized that the program will introduce great positive change to the physical and social environment, as it will make it healthier, cleaner, and safer. Similarly, assessing compatibility revealed that the program is consistent with the existing values, past experiences and needs of the students. Regarding complexity, they found it easy to understand as SHT and principal will attend training sessions and will be provided by the accreditation guide. When they assessed the trialability, they realized that they can try implementing the program for only one year on a limited basis by applying to the bronze level which requires meeting only $60 \%$ in every chapter of the accreditation. Finally, assessing observability indicated that the results of implementing this program might be visible as at least the school will be cleaner, healthier and safer. Consequently, they developed positive perception and attitude toward the accreditation.

\section{Decision stage:}

The main challenge was the lack of fund, in addition to the anticipated change resistance from teachers and students, and the bureaucratic structure of the school and the MOE. However, they proposed many alternatives to overcome these obstacles and made decision to join the accreditation. 


\section{Implementation stage:}

The accreditation institution provides the interested schools with accreditation guide which guides them in the implementation process. The accreditation guide is organized by the ten chapters and provides detailed description of the needed interventions under each chapter. Actions that have been undertaken under each chapter were as follow:

Chapter One (Leadership and management): the first step was establishing the school health committee (SHC), which consists of eight members: the principal, assistant, SHT, canteen manger, two student representatives and two community members. The SHT is responsible for communicating with the accreditation institution and has to regularly attend external meetings, and to document all accreditation interventions. All SHC members are responsible for initiating and monitoring all needed interventions.

Chapter Two (Safe school environment): the SHC members ensured the availability of windows' metal protection to protect students from accidental falling down. Also, they made sure that all windows are provided with net to prevent insects' entry to classes. They installed blinds and fixed non-working electricity. They repaired or replaced the broken desks and fixed the broken stairs and broken regions in the external yard, and installed the school main gate and extended and painted the school's wall. They installed a shelter in the yard to provide a sun-protected space for playing. Also, they painted the pedestrians' zoon, so that student can cross the road safely. Finally, they banned employees' parking inside the school yards.

Chapter Three (Healthy school environment): Nosmoking policy was activated and no-smoking signs were posted in school's corridors and main lobby. They added three water tanks to ensure sufficient water for sanitation and installed new coolers to ensure availability of sufficient clean drinking water.

Chapter Four (Clean school environment): Students and classes' teachers became accountable for their own classes' sanitation. A new cleaning schedule for the front and back yards has been developed and implemented to activate the students' role under the supervision of their teachers and to help the housekeepers organize their work and manage the emerged overload.

Chapter Five (Health education): a comprehensive educational program was developed with no less than two activities per month. The most needed topics were assessed to be nutrition and sanitation. Accordingly, different educational activities on these two topics were conducted. Among them are educational lecture about healthy food choices, hazards of unhealthy food, and the importance of eating healthy breakfast.

Chapter six (Staff and community participation): the SHC built good relations with the local community agencies and institutions in order to invest these relations to the benefits of students and the community. Also, they communicated with the local health care center, municipal council, traffic police, and drug-enforcement administration. Moreover, families were invited to join the regular staff-parents' meetings, and all recreational and sports events.

Chapter Seven (Health services): one of the store rooms was devoted to be a school health room, and it was fully equipped through a donation from a private local hospital. In collaboration with the local health care center, a routine physical exam was conducted at the beginning of the academic year for all students.

Chapter Eight (Social, mental and psychological support): the school counsellor was already available to deal with different social, mental and psychological problems. She conducts regular meetings with staff to discuss the most important topics based on her ongoing assessment of students' needs. Also, she provides counseling as needed and collaborates with families and different institutions to ensure students' wellness as needed. Furthermore, she usually conducts individualized interviews with students who have been referred from teachers and submit reports to the school principal to follow up with parents.

Chapter Nine (Nutrition): the school canteen reorganized, painted, and new sink was installed and a new refrigerator was bought. Unhealthy food and drinks were replaced by healthy food and drinks such as healthy sandwiches and milk. Also, all canteen personnel underwent an annual routine physical exam and mandated to wear the uniform. 
Chapter Ten (Physical activity): sports' classes were scheduled on the weekly schedule and seriously reactivated. Also, sport room has been established and equipped and some tools and equipment were gained as donations. Moreover, the front and back yards have been lined to become suitable for the different sports. Different sport teams were established and participated in the local sports competitions.

In this stage, the SHC was struggled mainly by the tight budget. To overcome this challenge, they adopted many strategies such as calling for budget release and increase from the MOE as schools applying to the accreditation have the priority for budget release. Also, the SHC received modest donations from teachers, students, and their families and received small fund from the local commercial institutions.

\section{Confirmation stage:}

Confirmation stage is the final stage, in which many tactics were applied to facilitate the long-term acceptance. Continuing education, psychological support, effective communication and close monitoring were key components in this stage.Continuous assessment of resistance and implementation of appropriate strategies to overcome were conducted. Also, students and staff were strongly encouraged to actively participate in designing and implementing different interventions according to their preferences. Moreover, ceremonies and rewards such as appreciation letters have been utilized to build loyalty and recognition which ultimately will enhance the confirmation of the accreditation. Finally, continuous monitoring and evaluation of resistance will be continued even after the change is fully adopted to ensure that staff and students will not lapse to old patterns of behaviors.

\section{Evaluation}

The evaluation of the accreditation was conducted in two levels: internal evaluation by an internal audit constitutes evaluators from the school health committee; and external evaluation by external audit sent from the accreditation agency which has the authority to provide the accreditation. The internal evaluation was conducted regularly every two months to check out the key performance indicators. External evaluation was conducted at the end of the academic year by the RAHS and the school was successfully accredited at the bronze level as it achieved at least $60 \%$ in every chapter of the accreditation standards. Also, one-year accreditation certificate and accreditation logo were granted.

\section{Conclusion and Implications for the school health}

Implementing a HPS program that is complex, multi-dimensional and multi-level in a developing country is a highly challenging experience. However, Adopting RDIT may help schools' administrations make informed decision on the light of the perceived attributes of the programs. Also, understanding the five stages of the theory can facilitate consciously proceeding throughout the implementation levels and anticipating the future events. Incorporating RDIT was of great benefit in understanding the change process itself, making informed decisions and organizing the implementation process.

Conflicts of Interest: the authors declare no conflict

\section{Funding: None}

Ethical Clearance: The study was approved by the Scientific Research Committee-the University of Jordan.

\section{References}

1. Ottawa Charter for Health Promotion. Health Promot 1987; 1(4).

2. Nutbeam D. Health promotion glossary.Health PromotInt 1998; 13(4): 349-364.

3. World Health Organization.Promoting health through schools. Report of a WHO expert committee on comprehensive school health education and promotion (WHO Technical Report Series 870). 1997; Geneva, Switzerland: Author.

4. Furley K,Goldfeld S. Cochrane Commentaries. The World Health Organization Health Promoting School framework is important for some child health outcomes. J Ped Child Health2017;53(2): 194-196.http://www.cochrane.org/CD008958/ BEHAV_the-who-health-promoting-schoolframework-for-improving-the-health-and-wellbeing-of-students-and-their-academic-achievement

5. Royal Health Awareness Society web site, retrieved from http://www.rhas.org.jo/contents/Healthy_ Schools_National_Accreditation.aspx\# 
176 Medico-legal Update, July-September 2021, Vol.21, No. 3

6. World Health Organization.Health Promoting School: An effective approach for early action on NCD risk factors. 2017; Geneva, Switzerland: Author. https://www.who.int/healthpromotion/ publications/health-promotion-school/en/

7. Rogers E. Diffusion of Innovations. 2003; Fifth edition. Free Press: New York. 